\title{
NARINGIN REVEALS AMELIORATIVE PROPERTY OVER ELEVATED OXIDATIVE STRESS LEVELS IN ANIMAL MODELS
}

\section{ZORAWAR SINGH*, ADESHWINDER KAUR, SHIVAM SHARMA}

\author{
Department of Zoology, Khalsa College, Amritsar, Punjab, India. E-mail: zorawarsinghs@rediffmail.com
}

Received: 16 February 2018, Revised and Accepted: 23 July 2018

\begin{abstract}
Oxidative stress (OxiS) has been implicated in the pathogenesis of many diseases. Free radicals interact with different cell components including DNA, proteins, and lipids to become stable. In this process, these free radicals damage the integrity of these biological moieties and result in various health implications. Naringin (NG), a naturally occurring phytochemical commonly found in grapefruit juice has been explored for its protective role against OxiS. In this short review paper, an attempt has been made to compile the study reports revealing the antioxidative nature of NG in different animal models. Studies have reported NG as a potential antioxidant in various health ailments including diabetes, cardiac fibrosis, cognitive dysfunction, and neurodegeneration.
\end{abstract}

Keywords: Phytocompounds, Naringin, Oxidative stress, Free radicals, Antioxidant.

(C) 2018 The Authors. Published by Innovare Academic Sciences Pvt Ltd. This is an open access article under the CC BY license (http://creativecommons. org/licenses/by/4. 0/) DOI: http://dx.doi.org/10.22159/ajpcr.2018.v11i12.25318

\section{INTRODUCTION}

Oxidative stress (OxiS) is defined as a state in biological systems in which oxidation exceeds the antioxidant systems of the body secondary to a loss of the balance between them [1]. It also causes hazardous events such as lipid peroxidation and oxidative DNA damage. Development of OxiS as a result of free oxygen radical generation has been implicated in the pathogenesis of many diseases including Parkinson's disease, Alzheimer's disease, atherosclerosis, heart failure, myocardial infarction, and even cancer [1]. A free radical is oxygencontaining a molecule that has one or more unpaired electrons, making it highly reactive with other molecules. Free radicals can chemically interact with cell components such as DNA, proteins or lipids, and steal their electrons to become stabilized. The reactive oxygen metabolites produced are more reactive than the original oxygen molecule and are called active oxygen species. Many daily habits are closely associated with OxiS which includes smoking [2-5], drinking [6-9], and an irregular diet [10-13]. The superoxide radical $\left(\cdot \mathrm{O}_{2}^{-}\right)$, one of the reactive oxygen species (ROS), is known to be generated in brain and is involved in the reduction of certain iron complexes including cytochrome C. Superoxide dismutase is a metalloenzyme catalytically eliminating superoxide radical as a first-line defense mechanism against 0xiS [14]. In the same way, nitric oxide (NO·) [15-18] and Peroxyl $\left(\mathrm{RO}_{2} \cdot\right)$ radicals [19] are highly unstable moieties also. These are formed in the human body and disrupt proteins and promote DNA damage [20-23]. ROS are also engaged in disruption of the integrity of polyunsaturated fatty acids. Hypochlorous acid, peroxynitrite, hydrogen peroxide, and ozone are the non-radical forms of ROS that can easily enter free radical reactions.

OxiS leads to many pathophysiological conditions in the body. Some of these are neurodegenerative diseases, gene mutations, atherosclerosis, and cancers [24,25]. Thus, various antioxidant defense mechanisms have developed in the process of evolution to cope up with the increasing OxiS levels. Different compounds have been identified which play a key role in minimizing the levels of OxiS. Flavonoid is the group of chemicals which possess different reported broad-spectrum therapeutic and pharmacological properties including free radical scavenging and antioxidant capacity. Naringin (NG) is a flavonoid which is widely distributed in plant foods. In its pure form, it exists as a yellow colored powder. NG has similar structure to hesperidin. It is mainly extracted from grapefruit and some other related citrus species. Its metabolite naringenin is ubiquitously distributed in plant foods and traditional Chinese medicines. Both NG and its metabolite naringenin have been reported to show broad spectrum of therapeutic and pharmacological properties including anti-inflammatory [26-30], free radical-scavenging [31-33], lipid-lowering [34,35], antioxidant [36-39], anti-fibrosis, and anti-obesity effects $[34,35,40]$. Recently, NG has been extensively checked for its antioxidant property in different animal models. In this particular paper, we have reviewed the latest research works highlighting the ameliorative property of NG on biological oxidative status (Table 1 )

Table 1: Diseases associated with 0xiS with respect to different organs

\begin{tabular}{ll}
\hline Body Part & Disease \\
\hline Brain & Alzheimer's disease \\
& Parkinson's disease \\
& Multiple Sclerosis \\
& Amyotrophic lateral sclerosis \\
& Obsessive compulsive disorder \\
& Attention deficit hyperactivity disorder \\
& Autism \\
Migraine \\
Insomnia \\
Depression \\
Dementia \\
Bi-polar disorder \\
Cancer \\
Heart attack \\
Stroke \\
High blood pressure \\
Atherosclerosis \\
Angina \\
Chronic kidney disease \\
Kidney & Renal Nephritis \\
& Wrinkles \\
& Acne \\
Eczema \\
Psoriasis \\
Dermatitis \\
Cancer \\
\hline
\end{tabular}


Table 1: Diseases associated with 0xiS with respect to different organs (Continued)

\begin{tabular}{ll}
\hline Body Part & Disease \\
\hline Multi-Organ & Diabetes \\
& Chronic fatigue \\
& Fibromyalgia \\
& Heavy metal toxicity \\
& Lyme disease \\
& Rheumatoid arthritis \\
& Osteoarthritis \\
Joints & Psoriatic arthritis \\
& Chronic inflammation \\
& Auto-immune disorders \\
Immune System & HIV \\
& Herpes \\
& Lupus \\
& Cancer \\
& Atherosclerosis \\
& Hypertension \\
Blood Vessels & Varicose veins \\
& Elevated Cholesterol and triglycerides \\
Asthma \\
CoPD \\
Lung & Allergies \\
Chronic bronchitis \\
Cancer \\
Macular degeneration \\
Retinal degeneration \\
Cataract \\
\end{tabular}

\section{STUDIES ON AMELIORATIVE NATURE OF NG AGAINST OXIS}

NG is a naturally occurring phytochemical commonly found in grapefruit juice with a number of health benefits [41]. It has been much explored by different research groups for its capability to ameliorate hazardous effects of various metals [42] as well as in different pathological conditions [43-45]. NG has been reported to mitigate cisplatin-induced OxiS and inflammatory response. Administration of NG (25, 50, and $100 \mathrm{mg} / \mathrm{kg}$ ) was able to attenuate deterioration in striatum tissue, abrogate antioxidant enzyme activities and suppressed the increase in malondialdehyde in rats [46]. NG has shown preventive effects against lipid peroxides and antioxidants [47]. Oral administration of $\mathrm{NG}(10,20$, and $40 \mathrm{mg} / \mathrm{kg})$ to isoproterenol exposed Wistar rats showed a considerable decrease in the levels of lipid peroxidation products and improved the antioxidant status [47]. NG is known for its anti-inflammatory $[46,48-50]$ and antioxidative nature $[43,45,51,52]$. Arsenic-induced hepatic and renal toxicity are reported to be reduced by anti-inflammatory and antioxidative nature of NG [53]. Different from other studies involving the ameliorative action of NG on oxidative status have also been summarized in Table 2 .

\section{Effect of NG on OXIS in diabetic models}

NG alleviated diabetic retinopathy symptoms as evidenced by the increased retinal ganglion cells and decreased GFAP level in rat retina. NG exhibited anti-inflammatory and antioxidative effects as revealed by the down-regulated pro-inflammatory cytokines, tumor necrosis factor-alpha, interleukin-1beta, and interleukin-6. Glutathione, superoxide dismutase, and catalase were reported to be upregulated [43]. Hyperglycemia promotes myocardial fibrotic lesions through upregulation of PKC and p38 in response to redox changes. NG was also shown to reduce hyperglycemia-induced cardiac fibrosis by relieving OxiS. Adebiyi et al. [57] investigated the effects of NG on

Table 2: Studies focused on ameliorative property of NG over OxiS

\begin{tabular}{|c|c|c|c|c|c|}
\hline S.no & Author name & Year & Model & Inference & Reference no. \\
\hline 1. & Oluwafeyisetan et al. & 2016 & Wistar rats & $\begin{array}{l}\text { NG ameliorated OxiS and NRTI-induced mitochondrial } \\
\text { damage }\end{array}$ & {$[54]$} \\
\hline 2. & Adil et al. & 2015 & Rats & $\begin{array}{l}\text { NG ameliorates sodium arsenite-induced renal and } \\
\text { hepatic toxicity and OxiS }\end{array}$ & [53] \\
\hline 3. & Jain and Parmar & 2011 & Rats & $\begin{array}{l}\text { NG showed anti-inflammatory and antioxidative in } \\
\text { nature }\end{array}$ & {$[55]$} \\
\hline 4. & $\begin{array}{l}\text { Rajadurai and Stanely Mainzen } \\
\text { Prince }\end{array}$ & 2006 & Wistar rats & $\begin{array}{l}\mathrm{NG} \text { possess anti-lipoperoxidative and antioxidant activity } \\
\text { in experimentally ISO-induced cardiac toxicity }\end{array}$ & {$[47]$} \\
\hline 5. & Liu et al. & 2017 & Diabetic rats & $\begin{array}{l}\text { NG attenuated inflammation and OxiS, reducing diabetic } \\
\text { retinopathy }\end{array}$ & {$[43]$} \\
\hline 6. & Viswanatha et al. & 2017 & Rodents & $\begin{array}{l}\text { NG play a beneficial role against OxiS-induced } \\
\text { neurobehavioral disorders and cognitive dysfunction }\end{array}$ & {$[44]$} \\
\hline 7. & Han et al. & 2017 & Rats & $\begin{array}{l}\text { NG attenuated early brain injury after experimental } \\
\text { subarachnoid hemorrhage by reducing OxiS and } \\
\text { inhibiting apoptosis }\end{array}$ & {$[56]$} \\
\hline 8. & Liu et al. & 2016 & Mice & $\begin{array}{l}\text { NG revealed protective role against ankylosing } \\
\text { spondylitis exerted through induction of ossification, } \\
\text { suppression of inflammation, and OxiS. }\end{array}$ & {$[45]$} \\
\hline 9. & Adebiyi et al. & 2016 & $\begin{array}{l}\text { Sprague } \\
\text { Dawley rats }\end{array}$ & $\begin{array}{l}\text { NG reduces hyperglycemia-induced cardiac fibrosis by } \\
\text { relieving OxiS }\end{array}$ & [57] \\
\hline 10. & Adebiyi et al. & 2015 & Wistar rats & $\begin{array}{l}\text { NG reverses metabolic complications associated with } \\
\text { NRTIs by ameliorating OxiS and apoptosis }\end{array}$ & [58] \\
\hline 11. & Chen et al. & 2015 & Rats & $\begin{array}{l}\text { NG alleviates diabetic kidney disease through inhibiting } \\
\text { OxiS and inflammatory reaction }\end{array}$ & {$[48]$} \\
\hline 12. & Adebiyi et al. & 2016 & $\begin{array}{l}\text { Sprague } \\
\text { Dawley rats }\end{array}$ & $\begin{array}{l}\text { NG mitigates cardiac hypertrophy by reducing OxiS and } \\
\text { Inactivating c-Jun Nuclear Kinase-1 protein in type } 1 \\
\text { diabetes }\end{array}$ & [59] \\
\hline 13. & Qi et al. & 2015 & Rats & $\begin{array}{l}\mathrm{NG} \text { ameliorates cognitive deficits through reducing OxiS } \\
\text { and pro-inflammatory in a type } 2 \text { diabetes }\end{array}$ & {$[52]$} \\
\hline 14. & Dhanya et al. & 2015 & $\begin{array}{l}\text { L6 Rat cell } \\
\text { line }\end{array}$ & $\begin{array}{l}\text { NG activated GSH synthesis through a novel antioxidant } \\
\text { defense mechanism preventing oxidative damage in } \\
\text { addition to its effect on glycemic control }\end{array}$ & {$[60]$} \\
\hline
\end{tabular}


Table 2: Studies focused on ameliorative property of NG over OxiS (Continued)

\begin{tabular}{|c|c|c|c|c|c|}
\hline S.no & Author name & Year & Model & Inference & Reference no. \\
\hline 15. & Chtourou et al. & 2015 & Rats & $\begin{array}{l}\text { NG revealed protective role against cisplatin-induced } \\
\text { OxiS, inflammatory response and apoptosis }\end{array}$ & {$[46]$} \\
\hline 16. & Golechha et al. & 2014 & Rats & $\begin{array}{l}\text { NG ameliorated pentylenetetrazol-induced seizures and } \\
\text { associated OxiS, inflammation and cognitive impairment }\end{array}$ & [49] \\
\hline 17. & Gopinath and Sudhandiran & 2012 & Rats & $\begin{array}{l}\text { NG modulates OxiS and inflammation in 3-nitropropionic } \\
\text { acid-induced neurodegeneration }\end{array}$ & {$[50]$} \\
\hline 18. & Mahmoud et al. & 2012 & Rats & $\begin{array}{l}\text { NG attenuated hyperglycemia-mediated OxiS and } \\
\text { pro-inflammatory response }\end{array}$ & {$[51]$} \\
\hline 19. & Akondi et al. & 2011 & Rats & $\begin{array}{l}\text { NG revealed suppressive effects on testicular } \\
\text { ischemia-reperfusion induced OxiS }\end{array}$ & {$[61]$} \\
\hline 20. & Jagetia and Reddy & 2011 & $\begin{array}{l}\text { Mouse liver } \\
\text { mitochondria }\end{array}$ & NG alleviated iron-induced OxiS & [42] \\
\hline 21. & Kumar et al. & 2010 & Mice & $\begin{array}{l}\text { NG alleviated cognitive impairment, mitochondrial } \\
\text { dysfunction, and OxiS induced by D-galactose }\end{array}$ & {$[62]$} \\
\hline
\end{tabular}

NG: Naringin, RT-PCR: Reverse transcription polymerase chain reaction, DPPH: 1,1-diphenyl-2-picrylhydrazyl, MAPK: Mitogen-activated protein kinase pathway, OxiS: Oxidative stress, LSD: Least significant difference, DNPH: 2,4-dinitrophenylhydrazine, GSH: Glutathione, NRTI: Nucleoside reverse transcriptase inhibitor, HUVECs: Human umbilical vein endothelial cells, ISO: Isoproterenol

hyperglycemia-induced myocardial fibrotic changes and its putative effects on PKC-beta and p38 protein expression in Type 1 rat model of diabetes. NG was described as to reduce OxiS, NADPH oxidase activity, cardiac fibrosis, PKC-beta, and p38 mitogen-activated protein kinase expression. Similarly, another study investigated the protective effect of NG against diabetic kidney disease elucidating its possible molecular mechanism. NG relieved the kidney injury, improved renal function, inhibited collagen formation and renal interstitial fibrosis and restrained OxiS by activating Nuclear factor-erythroid 2-related factor-2 (Nrf2) antioxidant pathway [48]. A study also reported the effect of NG on the regulation of diabetes-associated cognitive decline and its underlying mechanisms. An experimental diabetes mellitus rat model was induced by streptozoticin $(50 \mathrm{mg} / \mathrm{kg})$ and $\mathrm{NG}$ treatment (100 and $200 \mathrm{mg} / \mathrm{kg}$ ) for 16 weeks was given. A Morris water maze test was used to analyze the effects of NG on the cognitive deficit, and the results demonstrated that NG ameliorated cognitive deficits through OxiS, pro-inflammatory factors, and the peroxisome proliferatoractivated receptor gamma signaling pathway in the Type 2 diabetic rat model [52].

\section{Effect of NG on OXIS in neurodegenerative models}

Role of OxiS has been well documented in aging and related disorders such as Alzheimer's disease [62]. Bioflavonoids have been used in many researches used as neuroprotectants in the treatment of neurological disorders. NG has been reported to modulate OxiS and inflammation in 3-nitropropionic acid-induced neurodegeneration [50]. It also alleviated cognitive impairment and OxiS induced by D-galactose in mice [62]. Nrf2 mediated regulation of cellular antioxidant production play an important role in neuroprotection. Rats were injected with 3-nitropropionic acid $(10 \mathrm{mg} / \mathrm{kg}$ body weight/day, i.p.) for 2 weeks to develop neurodegeneration. Treatment with NG amended the reduced glutathione/oxidized glutathione ratio with an associated decrease in the levels of hydroxyl radical, hydro-peroxide, and nitrite [50]. OxiS and cognitive impairment are associated with PTZ-induced convulsions. The administration of PTZ induced myoclonic jerks and generalized tonic-clonic seizures. The study reported that NG significantly prolonged the induction of myoclonic jerks in a dose-dependent manner and NG $(80 \mathrm{mg} / \mathrm{kg}$, i.p.) pretreatment protected all rats. NG reduced brain MDA and TNF-alpha levels and conserved GSH [49]. 6-week NG (40 and $80 \mathrm{mg} / \mathrm{kg}$ ) treatment has also been reported to improve oxidative defense, and cognitive performance in D-galactose induced cognitive dysfunctional mice [62]. NG has been reported to be a potential anti-inflammatory agent as it showed a highest binding affinity $(8.6 \mathrm{Kcal} / \mathrm{mol})$ and satisfied the Lipinski's rule of five [63]. Like NG, Naringenin coadministration has also been reported to play a protective role against arsenic-induced toxicity in liver tissues of male rats [64].

\section{CONCLUSION}

OxiS is a biological state which is associated with the pathogenesis of many diseases. Free radicals damage the integrity of biological molecules including DNA, proteins, and lipids resulting in various health implications. A number of phytochemicals have been checked for their protective role against OxiS. In this short review paper, we have compiled the study reports revealing the antioxidative nature of NG. After review of studies, it has been found that NG is a natural potential antioxidant and its supplements can be used in various health disorders including diabetes, diabetic retinopathy, neurodegeneration, early brain injury, subarachnoid hemorrhage, cognitive dysfunction, cardiac fibrosis, cardiac hypertrophy, diabetic kidney, and ankylosing spondylitis.

\section{AUTHOR'S CONTRIBUTION}

All the authors contributed equally to the paper.

\section{CONFLICTS OF INTEREST}

The authors declare that there are no conflicts of interest.

\section{REFERENCES}

1. Singh Z, Karthigesu IP, Singh P, Kaur R. Use of malondialdehyde as a biomarker for assessing oxidative stress in different disease pathologies: A review. Iran J Pub Health 2014;43:7-16.

2. Ikonomidis I, Vlastos D, Kourea K, Kostelli G, Varoudi M, Pavlidis G, et al. Electronic cigarette smoking increases arterial stiffness and oxidative stress to a lesser extent than a single conventional cigarette: An acute and chronic study. Circulation 2018;137:303-6.

3. Niemann B, Rohrbach S, Miller MR, Newby DE, Fuster V, Kovacic JC, et al. Oxidative stress and cardiovascular risk: Obesity, diabetes, smoking, and pollution: Part 3 of a 3-part series. J Am Coll Cardiol 2017;70:230-51.

4. Gao X, Gào X, Zhang Y, Breitling LP, Schöttker B, Brenner H, et al. Associations of self-reported smoking, cotinine levels and epigenetic smoking indicators with oxidative stress among older adults: A population-based study. Eur J Epidemiol 2017;32:443-56.

5. Kamceva G, Arsova-Sarafinovska Z, Ruskovska T, Zdravkovska M, Kamceva-Panova L, Stikova E, et al. Cigarette smoking and oxidative stress in patients with coronary artery disease. Open Access Maced J Med Sci 2016;4:636-40.

6. Reddy VD, Padmavathi P, Bulle S, Hebbani AV, Marthadu SB, Venugopalacharyulu NC, et al. Association between alcohol-induced oxidative stress and membrane properties in synaptosomes: A protective role of vitamin E. Neurotoxicol Teratol 2017;63:60-5.

7. Teplova VV, Kruglov AG, Kovalyov LI, Nikiforova AB, Fedotcheva NI, Lemasters JJ, et al. Glutamate contributes to alcohol hepatotoxicity by enhancing oxidative stress in mitochondria. J Bioenerg Biomembr 2017;49:253-64

8. Barcia JM, Portolés S, Portolés L, Urdaneta AC, Ausina V, Pérez- 
Pastor GM, et al. Does oxidative stress induced by alcohol consumption affect orthodontic treatment outcome? Front Physiol 2017;8:22.

9. Hu Q, Wei J, Liu Y, Fei X, Hao Y, Pei D, et al. Discovery and identification of potential biomarkers for alcohol-induced oxidative stress based on cellular metabolomics. Biomed Chromatogr 2017;31: doi: 10.1002/bmc.3907.

10. Mojto V, Gvozdjakova A, Kucharska J, Rausova Z, Vancova O, Valuch J, et al. Effects of complete water fasting and regeneration diet on kidney function, oxidative stress and antioxidants. Bratisl Lek Listy 2018;119:107-11.

11. Ibitoye OB, Ajiboye TO. Dietary phenolic acids reverse insulin resistance, hyperglycaemia, dyslipidaemia, inflammation and oxidative stress in high-fructose diet-induced metabolic syndrome rats. Arch Physiol Biochem 2017;2017:1-8

12. Rossi M, Caruso F, Kwok L, Lee G, Caruso A, Gionfra F, et al. Protection by extra virgin olive oil against oxidative stress in vitro and in vivo. Chemical and biological studies on the health benefits due to a major component of the mediterranean diet. PLoS One 2017;12:e0189341.

13. Yang L, Lin W, Nugent CA, Hao S, Song H, Liu T, et al. Lingguizhugan decoction protects against high-fat-diet-induced nonalcoholic fatty liver disease by alleviating oxidative stress and activating cholesterol secretion. Int J Genomics 2017;2017:2790864.

14. Chung WH. Unraveling new functions of superoxide dismutase using yeast model system: Beyond its conventional role in superoxide radical scavenging. J Microbiol 2017;55:409-16.

15. Decroix L, Tonoli C, Soares DD, Descat A, Drittij-Reijnders MJ, Weseler AR, et al. Acute cocoa flavanols intake has minimal effects on exercise-induced oxidative stress and nitric oxide production in healthy cyclists: A randomized controlled trial. J Int Soc Sports Nutr 2017;14:28

16. El-Awady MS, Nader MA, Sharawy MH. The inhibition of inducible nitric oxide synthase and oxidative stress by agmatine attenuates vascular dysfunction in rat acute endotoxemic model. Environ Toxicol Pharmacol 2017;55:74-80.

17. Gecit İ, Eryılmaz R, Kavak S, Meral İ, Demir H, Pirinççi N, et al. The prolidase activity, oxidative stress, and nitric oxide levels of bladder tissues with or without tumor in patients with bladder cancer. J Membr Biol 2017;250:455-9.

18. Hanedan B, Kirbas A, Kandemir FM, Aktas MS, Yildiz A. Evaluation of arginase activity, nitric oxide and oxidative stress status in sheep with contagious agalactia. Acta Vet Hung 2017;65:394-401.

19. Ben Othman S, Katsuno N, Kitayama A, Fujimura M, Kitaguchi K, Yabe $\mathrm{T}$, et al. Water-soluble fractions from defatted sesame seeds protect human neuroblast cells against peroxyl radicals and hydrogen peroxide-induced oxidative stress. Free Radic Res 2016;50:949-58.

20. Lang JY, Ma K, Guo JX, Sun H. Oxidative stress induces B lymphocyte DNA damage and apoptosis by upregulating p66shc. Eur Rev Med Pharmacol Sci 2018;22:1051-60.

21. Hajra S, Patra AR, Basu A, Bhattacharya S. Prevention of doxorubicin (DOX)-induced genotoxicity and cardiotoxicity: Effect of plant derived small molecule indole-3-carbinol (I3C) on oxidative stress and inflammation. Biomed Pharmacother 2018;101:228-43.

22. Paravani EV, Simoniello MF, Poletta GL, Zolessi FR, Casco VH. Cypermethrin: Oxidative stress and genotoxicity in retinal cells of the adult zebrafish. Mutat Res 2018;826:25-32

23. Douiev L, Abu-Libdeh B, Saada A. Cytochrome c oxidase deficiency, oxidative stress, possible antioxidant therapy and link to nuclear DNA damage. Eur J Hum Genet 2018;26:579-81.

24. Lin S, Ren A, Wang L, Huang Y, Wang Y, Wang C, et al. Oxidative stress and apoptosis in benzo[a]pyrene-induced neural tube defects. Free Radic Biol Med 2018;116:149-58.

25. Robson R, Kundur AR, Singh I. Oxidative stress biomarkers in type 2 diabetes mellitus for assessment of cardiovascular disease risk. Diabetes Metab Syndr 2018;12:455-62.

26. Alam MA, Subhan N, Rahman MM, Uddin SJ, Reza HM, Sarker SD, et al. Effect of citrus flavonoids, naringin and naringenin, on metabolic syndrome and their mechanisms of action. Adv Nutr 2014;5:404-17.

27. Golechha M, Sarangal V, Bhatia J, Chaudhry U, Saluja D, Arya DS, et al. Naringin ameliorates pentylenetetrazol-induced seizures and associated oxidative stress, inflammation, and cognitive impairment in rats: Possible mechanisms of neuroprotection. Epilepsy Behav 2014;41:98-102.

28. Jiao HY, Su WW, Li PB, Liao Y, Zhou Q, Zhu N, et al. Therapeutic effects of naringin in a guinea pig model of ovalbumin-induced coughvariant asthma. Pulm Pharmacol Ther 2015;33:59-65.

29. Ren X, Shi Y, Zhao D, Xu M, Li X, Dang Y, et al. Naringin protects ultraviolet B-induced skin damage by regulating p38 MAPK signal pathway. J Dermatol Sci 2016;82:106-14

30. Zhao Y, Li Z, Wang W, Zhang H, Chen J, Su P, et al. Naringin protects against cartilage destruction in osteoarthritis through repression of NF- $\kappa$ B signaling pathway. Inflammation 2016;39:385-92.

31. Oluwafeyisetan A, Olubunmi A, Peter O. Naringin ameliorates HIV-1 nucleoside reverse transcriptase inhibitors- induced mitochondrial toxicity. Curr HIV Res 2016;14:506-16.

32. Ozyürek M, Akpınar D, Bener M, Türkkan B, Güçlü K, Apak R, et al. Novel oxime based flavanone, naringin-oxime: Synthesis, characterization and screening for antioxidant activity. Chem Biol Interact 2014;212:40-6.

33. Panda S, Kar A. Antithyroid effects of naringin, hesperidin and rutin in 1-T4 induced hyperthyroid rats: Possible mediation through 5'DI activity. Pharmacol Rep 2014;66:1092-9.

34. Guo X, Liu J, Cai S, Wang O, Ji B. Synergistic interactions of apigenin, naringin, quercetin and emodin on inhibition of 3T3-L1 preadipocyte differentiation and pancreas lipase activity. Obes Res Clin Pract 2016; 10:327-39

35. Raffoul-Orozco AK, Ávila-González AE, Rodríguez-Razón CM, García-Cobian TA, Pérez-Guerrero EE, García-Iglesias T, et al. Combination effect naringin and pravastatin in lipid profile and glucose in obese rats. Life Sci 2018;193:87-92.

36. Guihua X, Shuyin L, Jinliang G, Wang S. Naringin protects ovalbumininduced airway inflammation in a mouse model of asthma. Inflammation 2016;39:891-9.

37. Gürsul C, Ekinci Akdemir FN, Akkoyun T, Can İ, Gül M, Gülçin İ, et al. Protective effect of naringin on experimental hindlimb ischemia/ reperfusion injury in rats. J Enzyme Inhib Med Chem 2016;31:56-61.

38. Iturriaga L, Olabarrieta I, Castellan A, Gardrat C, Coma V. Active naringin-chitosan films: Impact of UV irradiation. Carbohydr Polym 2014; $110: 374-81$

39. Kim TH, Jang SJ, Chung HW, Kim HJ, Yong HI, Choe W, et al. Enhancement of antioxidant effects of naringin after atmospheric pressure dielectric barrier discharge plasma treatment. Bioorg Med Chem Lett 2015;25:1236-9.

40. Wang D, Yan J, Chen J, Wu W, Zhu X, Wang Y, et al. Naringin improves neuronal insulin signaling, brain mitochondrial function, and cognitive function in high-fat diet-induced obese mice. Cell Mol Neurobiol 2015;35:1061-71.

41. Singh Z, Sharma S, Kaur A. Antitoxic effects of naringin: A flavonoid with diverse biological activities. World J Pharm Res 2018;7:484-9.

42. Jagetia GC, Reddy TK. Alleviation of iron induced oxidative stress by the grape fruit flavanone naringin in vitro. Chem Biol Interact 2011;190:121-8.

43. Liu L, Zuo Z, Lu S, Liu A, Liu X. Naringin attenuates diabetic retinopathy by inhibiting inflammation, oxidative stress and NF- $\kappa B$ activation in vivo and in vitro. Iran J Basic Med Sci 2017;20:813-21.

44. Viswanatha GL, Shylaja H, Moolemath Y. The beneficial role of naringin- a citrus bioflavonoid, against oxidative stress-induced neurobehavioral disorders and cognitive dysfunction in rodents: A systematic review and meta-analysis. Biomed Pharmacother 2017;94:909-29.

45. Liu K, Wu L, Shi X, Wu F. Protective effect of naringin against ankylosing spondylitis via ossification, inflammation and oxidative stress in mice. Exp Ther Med 2016;12:1153-8.

46. Chtourou Y, Aouey B, Kebieche M, Fetoui H. Protective role of naringin against cisplatin induced oxidative stress, inflammatory response and apoptosis in rat striatum via suppressing ROS-mediated NF- $\kappa$ B and P53 signaling pathways. Chem Biol Interact 2015;239:76-86.

47. Rajadurai M, Stanely Mainzen Prince P. Preventive effect of naringin on lipid peroxides and antioxidants in isoproterenol-induced cardiotoxicity in Wistar rats: Biochemical and histopathological evidences. Toxicology 2006;228:259-68.

48. Chen F, Zhang N, Ma X, Huang T, Shao Y, Wu C, et al. Naringin alleviates diabetic kidney disease through inhibiting oxidative stress and inflammatory reaction. PLoS One 2015;10:e143868.

49. Golechha M, Sarangal V, Bhatia J, Chaudhry U, Saluja D, Arya DS, et al. Naringin ameliorates pentylenetetrazol-induced seizures and associated oxidative stress, inflammation, and cognitive impairment in rats: Possible mechanisms of neuroprotection. Epilepsy Behav 2014:41:98-102.

50. Gopinath K, Sudhandiran G. Naringin modulates oxidative stress and inflammation in 3-nitropropionic acid-induced neurodegeneration through the activation of nuclear factor-erythroid 2-related factor-2 signalling pathway. Neuroscience 2012;227:134-43.

51. Mahmoud AM, Ashour MB, Abdel-Moneim A, Ahmed OM. Hesperidin and naringin attenuate hyperglycemia-mediated oxidative stress and 
proinflammatory cytokine production in high fat fed/streptozotocininduced Type 2 diabetic rats. J Diabetes Complications 2012;26:483-90.

52. Qi Z, Xu Y, Liang Z, Li S, Wang J, Wei Y, et al. Naringin ameliorates cognitive deficits via oxidative stress, proinflammatory factors and the PPAR $\gamma$ signaling pathway in a Type 2 diabetic rat model. Mol Med Rep 2015;12:7093-101.

53. Adil M, Kandhare AD, Visnagri A, Bodhankar SL. Naringin ameliorates sodium arsenite-induced renal and hepatic toxicity in rats: Decisive role of KIM-1, caspase-3, TGF- $\beta$, and TNF- $\alpha$. Ren Fail 2015;37:1396-407.

54. Oluwafeyisetan A, Olubunmi A, Peter O. Naringin ameliorates HIV-1 nucleoside reverse transcriptase inhibitors- induced mitochondrial toxicity. Curr HIV Res 2016;14:506-16.

55. Jain M, Parmar HS. Evaluation of antioxidative and anti-inflammatory potential of hesperidin and naringin on the rat air pouch model of inflammation. Inflamm Res 2011;60:483-91.

56. Han Y, Su J, Liu X, Zhao Y, Wang C, Li X, et al. Naringin alleviates early brain injury after experimental subarachnoid hemorrhage by reducing oxidative stress and inhibiting apoptosis. Brain Res Bull 2017;133:42-50

57. Adebiyi OA, Adebiyi OO, Owira PM. Naringin reduces hyperglycemiainduced cardiac fibrosis by relieving oxidative stress. PLoS One 2016;11:e 0149890

58. Adebiyi OO, Adebiyi OA, Owira PM. Naringin reverses hepatocyte apoptosis and oxidative stress associated with HIV-1 nucleotide reverse transcriptase inhibitors-induced metabolic complications. Nutrients 2015;7:10352-68.

59. Adebiyi AO, Adebiyi OO, Owira PM. Naringin mitigates cardiac hypertrophy by reducing oxidative stress and inactivating c-jun nuclear kinase-1 protein in Type I diabetes. J Cardiovasc Pharmacol 2016;67:136-44.

60. Dhanya R, Arun KB, Nisha VM, Syama HP, Nisha P, Santhosh Kumar TR, et al. Preconditioning L6 muscle cells with naringin ameliorates oxidative stress and increases glucose uptake. PLoS One 2015;10:e132429.

61. Akondi BR, Challa SR, Akula A. Protective effects of rutin and naringin in testicular ischemia-reperfusion induced oxidative stress in rats. J Reprod Infertil 2011;12:209-14.

62. Kumar A, Prakash A, Dogra S. Naringin alleviates cognitive impairment, mitochondrial dysfunction and oxidative stress induced by D-galactose in mice. Food Chem Toxicol 2010;48:626-32

63. Pany S, Pal A, Sahu PK. In Silico analysis of cyclooxygenase inhibitory activity of some natural molecules. Int J Pharm Pharm Sci 2013:5:975-1491.

64. Mohammad SA. Hepatoprotective effect and antioxidant capacity of naringenin on arsenic-induced liver injury in rats. Int J Pharm Pharm Sci 2016;8:975-1491. 